Supporting information

\title{
Maternal and cord blood metabolite associations with gestational weight gain and pregnancy health outcomes
}

Jane Shearer ${ }^{1,2 \star}$, Matthias S. Klein ${ }^{3,4}$, Hans J. Vogel ${ }^{4}$, Shuhiba Mohammad ${ }^{5}$, Shannon Bainbridge $^{6,7}$, Kristi B. Adamo ${ }^{5,8}$

${ }^{1}$ Department of Biochemistry and Molecular Biology. Faculty of Kinesiology, Cumming School of Medicine, University of Calgary, Calgary AB, Canada

${ }^{2}$ Alberta Children's Hospital Research Institute, University of Calgary, Calgary AB, Canada ${ }^{3}$ Department of Food Science and Technology, The Ohio State University, Columbus $\mathrm{OH}$, USA

${ }^{4}$ Department of Biological Sciences. Faculty of Science, University of Calgary, Calgary AB, Canada

${ }^{5}$ School of Human Kinetics, Faculty of Health Sciences, University of Ottawa, Ottawa ON, Canada

${ }^{6}$ Interdisciplinary School of Health Sciences, Faculty of Health Sciences, University of Ottawa, Ottawa ON, Canada

${ }^{7}$ Department of Cellular and Molecular Medicine, Faculty of Medicine, University of Ottawa, Ottawa ON, Canada

${ }^{8}$ Department of Pediatrics, Faculty of Medicine, University of Ottawa, Ottawa ON, Canada

*Corresponding Author. Telephone: +1 403220 3431, Facsimile: +1 403284 3553, Email: jshearer@ucalgary.ca 


\section{Table of Contents}

Figure S1. Example of serum signals showing strong inter-spectra positional changes.

Table S1. Signals correlated to gestational weight gain (GWG). 


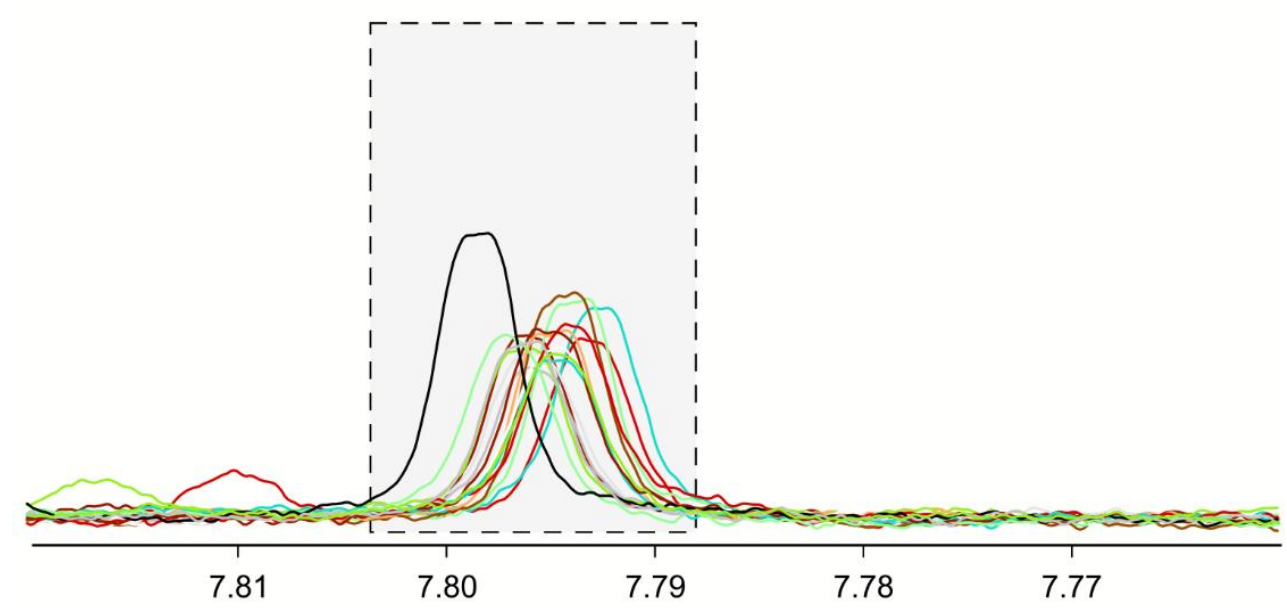

Figure S1. Example of serum signals showing strong inter-spectra positional changes. Signals within the dashed box were summed to account for this signal's variable position in the data set. 
Table S1. Signals correlated to gestational weight gain (GWG). Shown are signals that were significantly correlated to GWG after correction for multiple testing, and their respective raw $p$-values and coefficients for all factors of the linear model.

\begin{tabular}{|c|c|c|c|c|c|c|c|}
\hline \multirow{2}{*}{$\begin{array}{c}\text { Chemical } \\
\text { shift } \\
{[\mathrm{ppm}]}\end{array}$} & \multirow{2}{*}{$\begin{array}{l}\text { Metabolite } \\
\text { ID }\end{array}$} & \multicolumn{3}{|c|}{ Raw p-value } & \multicolumn{3}{|c|}{ Coefficient } \\
\hline & & GWG & BMI & GWG:BMI & GWG & BMI & GWG:BMI \\
\hline 7.3575 & $?$ & 0.00472 & 0.33417 & 0.29272 & $-6.29 \mathrm{E}-06$ & $-2.12 \mathrm{E}-05$ & 3.43E-07 \\
\hline 7.3025 & $?$ & 0.00415 & 0.24505 & 0.87313 & $1.45 \mathrm{E}-06$ & 6.87E-06 & 4.23E-08 \\
\hline 2.8775 & $?$ & 0.00203 & 0.00351 & 0.16805 & 9.99E-06 & $5.09 E-05$ & $-2.96 \mathrm{E}-07$ \\
\hline 2.3775 & pyruvate* & 0.00238 & 0.04824 & 0.80393 & $9.01 \mathrm{E}-05$ & 0.0005173 & $-1.36 \mathrm{E}-06$ \\
\hline 2.3675 & $?$ & 0.00078 & 0.00000 & 0.97621 & $2.96 \mathrm{E}-06$ & 0.0001021 & $1.62 \mathrm{E}-08$ \\
\hline 2.2775 & $?$ & 0.00357 & 0.00420 & 0.51568 & $-6.45 \mathrm{E}-06$ & $2.75 \mathrm{E}-05$ & 3.97E-07 \\
\hline 2.2675 & $?$ & 0.00145 & 0.05225 & 0.84855 & $2.80 \mathrm{E}-06$ & $2.93 \mathrm{E}-05$ & $1.08 \mathrm{E}-07$ \\
\hline 2.2625 & $?$ & 0.00052 & 0.02456 & 0.61112 & $-1.37 \mathrm{E}-06$ & $1.54 \mathrm{E}-05$ & $2.33 \mathrm{E}-07$ \\
\hline 2.2575 & valine* & 0.00005 & 0.03134 & 0.86362 & $7.06 \mathrm{E}-06$ & 3.47E-05 & $-6.35 E-08$ \\
\hline 2.2525 & valine & 0.00139 & 0.02309 & 0.22296 & 1.37E-05 & $6.15 \mathrm{E}-05$ & $-3.83 E-07$ \\
\hline 2.2475 & valine & 0.00273 & 0.02417 & 0.33372 & $1.29 \mathrm{E}-05$ & $6.22 \mathrm{E}-05$ & $-3.50 \mathrm{E}-07$ \\
\hline 2.1075 & $?$ & 0.00534 & 0.00150 & 0.26300 & $-7.47 \mathrm{E}-06$ & $4.08 \mathrm{E}-06$ & $3.38 \mathrm{E}-07$ \\
\hline 2.0975 & $?$ & 0.00180 & 0.09848 & 0.05325 & $-1.50 \mathrm{E}-05$ & $-4.26 \mathrm{E}-05$ & $6.63 \mathrm{E}-07$ \\
\hline 2.0625 & glut & 0.00455 & 0.00001 & 0.71415 & $6.78 \mathrm{E}-06$ & 0.0001017 & $-1.73 E-07$ \\
\hline 1.6425 & $?$ & 0.00491 & 0.02261 & 0.08795 & $-1.05 \mathrm{E}-05$ & $-2.10 \mathrm{E}-05$ & $4.53 \mathrm{E}-07$ \\
\hline 1.6375 & $?$ & 0.00012 & 0.14543 & 0.00556 & $-1.77 \mathrm{E}-05$ & $-5.88 \mathrm{E}-05$ & $7.70 \mathrm{E}-07$ \\
\hline 1.5875 & $?$ & 0.00320 & 0.20025 & 0.78572 & $8.30 \mathrm{E}-07$ & $6.40 \mathrm{E}-06$ & $8.85 \mathrm{E}-08$ \\
\hline 1.5825 & $?$ & 0.00439 & 0.79320 & 0.81207 & $4.54 \mathrm{E}-06$ & 8.07E-06 & $-6.11 E-08$ \\
\hline 1.5175 & $?$ & 0.00044 & 0.74045 & 0.06264 & $-1.62 \mathrm{E}-05$ & $-6.96 \mathrm{E}-05$ & $7.93 \mathrm{E}-07$ \\
\hline 1.5125 & $?$ & 0.00364 & 0.39946 & 0.05476 & $-2.11 \mathrm{E}-05$ & $-7.43 \mathrm{E}-05$ & $9.41 \mathrm{E}-07$ \\
\hline 1.5075 & lysine* & 0.00014 & 0.38848 & 0.67623 & $1.28 \mathrm{E}-06$ & $-3.49 \mathrm{E}-06$ & $1.62 \mathrm{E}-07$ \\
\hline 1.5025 & lysine & 0.00087 & 0.52714 & 0.75613 & $1.64 \mathrm{E}-06$ & $-2.76 \mathrm{E}-06$ & $1.21 \mathrm{E}-07$ \\
\hline 1.4525 & $?$ & 0.00062 & 0.67011 & 0.45478 & $-2.80 \mathrm{E}-06$ & $-3.92 \mathrm{E}-05$ & $3.45 \mathrm{E}-07$ \\
\hline 1.4075 & $?$ & 0.00263 & 0.11796 & 0.97558 & $4.88 \mathrm{E}-06$ & $2.63 \mathrm{E}-05$ & $-1.38 \mathrm{E}-08$ \\
\hline 1.3625 & $?$ & 0.00273 & 0.00001 & 0.31374 & $-1.10 \mathrm{E}-05$ & $3.83 \mathrm{E}-05$ & $4.86 \mathrm{E}-07$ \\
\hline 1.1625 & ? & 0.00400 & 0.36357 & 0.34066 & $9.93 \mathrm{E}-06$ & $3.27 \mathrm{E}-05$ & $-2.58 \mathrm{E}-07$ \\
\hline 0.9575 & ? & 0.00325 & 0.76315 & 0.30762 & $-2.54 \mathrm{E}-05$ & -0.000128 & $1.53 \mathrm{E}-06$ \\
\hline 0.9475 & $?$ & 0.00010 & 0.01639 & 0.82131 & $4.85 \mathrm{E}-06$ & 4.70E-05 & $1.60 \mathrm{E}-07$ \\
\hline 0.9375 & $?$ & 0.00015 & 0.00831 & 0.28367 & $2.65 \mathrm{E}-05$ & 0.0001243 & $-6.77 \mathrm{E}-07$ \\
\hline 0.9325 & $?$ & 0.00009 & 0.00753 & 0.62792 & $-4.49 \mathrm{E}-07$ & 3.70E-05 & 3.39E-07 \\
\hline 0.8575 & $?$ & 0.00290 & 0.16299 & 0.63788 & $6.46 \mathrm{E}-06$ & 2.61E-05 & $-1.31 \mathrm{E}-07$ \\
\hline 0.8475 & $?$ & 0.00291 & 0.55450 & 0.49878 & $9.25 \mathrm{E}-06$ & 2.59E-05 & $-2.09 E-07$ \\
\hline
\end{tabular}

* signals that were used in the linear modeling of GWG 